\title{
Attitude Change in Competitive Framing Environments? Open-/Closed-Mindedness, Framing Effects, and Climate Change
}

\author{
Erik C. Nisbet ${ }^{1}$, P. S. Hart ${ }^{2}$, Teresa Myers ${ }^{3}$, \& Morgan Ellithorpe ${ }^{1}$ \\ 1 School of Communication, The Ohio State University, Columbus, OH 43201, USA \\ 2 Department of Communication Studies, University of Michigan, Ann Arbor, MI, USA \\ 3 Center for Climate Change Communication, George Mason University, Fairfax, VA, USA
}

\begin{abstract}
Framing scholarship on policy issues has primarily focused on how competitive message environments alter framing effects or how individual differences moderate the impact of frames. This study combines both of these focal areas by examining how individual open/closed-mindedness moderates framing effects about climate change within competitive and noncompetitive framing contexts. Contrary to previous scholarship, our experimental study finds effects on attitudes in the competitive framing condition, but not the noncompetitive framing condition. The framing effects found in the competitive condition were contingent upon individual differences in open-/closed-mindedness. Analysis shows that individual open-/closed-mindedness influences framing effects in part by altering the effects of frame exposure on the perceived costs and benefits of government climate policies.
\end{abstract}

doi:10.1111/jcom.12040

Over the last 20 years, a significant amount of scholarship within the field of communication has investigated the influence of framed messages on audience attitudes and behaviors. However, an emerging critique of much of this research questions its external validity, as experimental participants are typically exposed to single-sided messages that do not realistically model the competitive message environments in which most individuals are embedded. There is currently a dearth of research examining how framing effects may operate differently within competitive message environments compared to noncompetitive environments. Furthermore, to date, scant research has examined how individual differences may influence message processing within competitive framing environments.

This study aims to address these gaps in the framing literature by examining how framing may influence support for climate mitigation policies in both competitive and noncompetitive message environments. Furthermore, we evaluate how individual

Corresponding author: Erik C. Nisbet; e-mail: nisbet.5@osu.edu 
open-/closed-mindedness may moderate framing effects on decision-making, and how this moderation may vary across differing degrees of message competition. Thus, this study combines two parallel tracks of recent framing scholarship that have attempted to understand the boundaries of framing effects.

\section{Framing and message competition}

Framing research has emerged across a range of disciplines as an analytical framework to unpack socially constructed schemas that give meaning to issues or events by presenting "a central organizing idea" (Gamson \& Modogliani, 1989). These "interpretive packages" may provide specific problem definitions, diagnose causes, and/or suggest solutions for individuals employing those frames when constructing meaning, processing information, and making evaluations or decisions (Entman, 2004). Framing research has the advantage of explanatory power at both the macro, or contextual, and micro, or individual, levels of analysis (Benford \& Snow, 2000; Chong \& Druckman, 2007a; Scheufele \& Tewksbury, 2007).

At the institutional level of analysis, frames are constructed, tailored, and communicated by a variety of competing social actors (e.g., politicians, advocacy organizations, corporations, etc.) (Scheufele \& Tewksbury, 2007). These processes of meaning construction (i.e., framing building) result in competitive frame contests between social actors attempting to shape public attitudes about an issue, topic, or event and spur citizen mobilization (Benford \& Snow, 2000; Scheufele \& Tewksbury, 2007). For example, to address climate change advocates for new government regulations have often focused on potential environmental disasters stemming from climate change, while opponents of regulation have focused on communicating the possible economic costs of such regulation (Nisbet, 2009). Linking the macro and micro, framing theorists have attempted to explicate how these "frames in communication" are strategically constructed and communicated with the goal of influencing audiences to use specific interpretive "frames in thought" when making sense of an issue, topic, or problem (Chong \& Druckman, 2007a, p. 106). However, most of the experimental framing research designed to investigate framing processes and effects at the microlevel of analysis has failed to take into account the competitive message environments at the macrolevel of analysis that often surround the topics about which framing effects are examined. This lacuna in the literature has been the focus of an emerging critique by several scholars in recent years who have questioned the external validity of experimental framing research that does not allow for individuals being exposed to competing frames simultaneously in "real world" message environments within its research design (e.g., Borah, 2011b; Chong \& Druckman, 2007b, 2007c; Sniderman \& Theriault, 2004).

These critics argue that framing experiments that adopt a "one-sided" message design testing the effect of a frame compared to a control group or a separate frame condition overestimate framing effects on attitude change. These critics have, in turn, demonstrated that framing effects may be diminished or altogether negated when audiences are exposed to competing frames, especially when audiences are 
exposed to frames of similar argumentative strength (Borah, 2011b; Chong and Druckman, 2007b, 2007c; Sniderman \& Theriault, 2004).

Though some studies in recent years have attempted to explicate framing effects and processes within competitive message contexts (i.e., Borah, 2011b; Chong and Druckman, 2007c), a recent review of the framing literature (Borah, 2011a) found a scant number of peer-reviewed studies (only $3.2 \%$ of 379 articles analyzed) examining competitive framing process and effects, demonstrating that further research in this area is greatly needed. Therefore, in this study we test the hypothesis that exposure to a framed message in a noncompetitive message environment will more likely result in attitude change compared to exposure to a framed message in a competitive message environment (H1).

\section{Open-/closed-mindedness and attitude change}

In addition to message competition, a common area of framing research is how individual characteristics or traits may moderate framing effects (Borah, 2011a; Chong and Druckman, 2007a). However, most of these potential moderators of framing effects have been tested by one-sided framing studies and not with two-sided studies in a competitive message context (Borah, 2011b). Thus, how individual differences may moderate framing effects within competitive message contexts is greatly underresearched.

In this context, we turn our attention to the individual difference variable of "open-/closed-mindedness," part of an overarching concept known as need for cognitive closure (Kruglanski, 2004; Webster \& Kruglanski, 1994). This concept has the potential to play a significant role in how audiences may process information, especially when considering political persuasion (Feldman et al., 2012; Holbert \& Hansen, 2006). Need for cognitive closure is defined by Richter and Kruglanski (2004) as "a desire for an answer to a question on a given topic, any answer" (p. 102). People who are low in need for cognitive closure can be considered "open-minded," while those who are high can be considered "closed-minded" (Kruglanski, 2004). In general, people who are closed-minded are motivated to process quickly and shallowly in an effort to draw any acceptable conclusion. In contrast, open-minded people are motivated to think about as much of the available data as they can, appreciate ambiguity, and enjoy drawing out the decision process (Kruglanski, 2004).

In terms of persuasion and attitude change, people who are closed-minded, as compared to those who are open-minded, tend to support the status quo and are more resistant to change (Jost \& Hunyady, 2005; Sinatra, Kardash, Taasoobshirazi, \& Lombardi, 2011), are less likely to be persuaded under conditions where they have a prior opinion base (Kruglanski, Webster, \& Klem, 1993), and also tend to require a smaller amount of information in order to make decisions (Choi, Koo, Choi, \& Auh, 2008). Kruglanski (2004) describes the closed-minded as engaging in a process in which they might briefly consider the arguments and then stop as soon as an acceptable conclusion is reached, or in other cases simply seize on prior opinions and discount new information that may be inconsistent. On the other hand, open-minded 
individuals are more likely to examine all aspects of a topic before making a decision and to process information more systematically. Based on this research, therefore, in general we should expect that individual open-/closed-mindedness will moderate the influence of message frames on attitude change, such that attitude change is more likely to occur among open-minded individuals (H2).

\section{Framing climate change and open-/closed-mindedness}

Beyond testing our first two hypotheses, we also aim to examine how our two sets of variables, contextual factors (message competition) and individual differences (open/closed-mindedness), intersect to influence attitudinal responses to message frames. For this examination we have selected the policy issue of climate change mitigation. Over the past several years the political discourse around the issue of climate change mitigation has been dominated by competing messages over the environmental, energy, and economic consequences of proposed government policies (Moser, 2010; Nisbet, 2009) and thus is an apt case study for understanding opinion formation within a competitive framing environment.

Furthermore, this frame contest has resulted in polarized public opinion about the issue, with support or opposition to climate change mitigation commonly dependent on whether individuals focus on the perceived costs or benefits of addressing climate change (Kahn and Kotchen, 2010; Sunstein, 2006; Weber, 2010). Therefore, we posit the perceived costs and benefits of government action on climate change mitigation will mediate the relationship between message frame exposure and attitudes about climate change policies (H3).

Previous scholarship also suggests that open-/closed-mindedness may specifically influence attitude formation within competitive message environments. For example, Chong and Druckman (2007b) argue that competitive message environments are more likely to "stimulate individuals to deliberate on the merits of alternative interpretations" (p. 651), which is more likely to happen among open-minded individuals than closed-minded, according to Kruglanski (2004). In other words, confirmation bias is less likely to occur among open-minded individuals in a competitive message environment as they are more likely to attend to and process a greater amount of available information, rather than seizing on a smaller amount of information that aligns with or confirms pre-existing attitudes.

In addition, open-/closed-mindedness may influence how audiences attend to competing message frames about climate change. Richter and Kruglanski (2004) suggest a relationship between need for closure and risk aversion, in that they argue that people who are induced to have a high need for closure due to time constraints or cognitive load become more risk averse. There is a possibility, therefore, that people who are high in need for cognitive closure may weigh the costs more than the benefits, even when costs are not objectively very high. In fact, people in general tend to be risk and loss averse, meaning that the costs tend to outweigh the benefits in a decision-making process even if the rational choice is to choose the side with more benefits (Kahneman \& Tversky, 1984). Thus, when considering competing message 
frames about climate change mitigation, open-minded individuals are more likely to perceive the benefits of climate change mitigation compared to closed-minded individuals - and therefore closed-minded individuals are more likely to prefer the status quo (H4). Taken together, $\mathrm{H} 3$ and $\mathrm{H} 4$ represent a moderated-mediation model of framing effects on audience attitudes about climate change policies (e.g., Hart \& Nisbet, 2012; Preacher et al., 2007). This model occurs when an audience predisposition (i.e., open-/closed-mindedness) moderates the influence of message exposure on an intervening mediating variable (i.e., perceived costs-benefits of climate change mitigation) on our dependent variable of interest (i.e., climate change mitigation policy).

\section{Method}

\section{Research stimulus}

For our study we created three 45-second videos that communicated common message frames found on both sides of the debate about climate change policy in the United States. By using a video, rather than textual, stimulus we aimed to create a set of "natural" message frames, as television serves as the primary channel of political communication in the United States. Two pro-climate change mitigation videos were created, one framed in terms of environmental disaster (i.e., melting ice caps, animal extinction, etc.) and the other framed in terms of national security (i.e., energy independence, global instability, terrorism, etc.) (see Moser, 2010; Nisbet, 2009; Zia \& Todd, 2010). Though each pro-climate mitigation message frame emphasized different negative impacts of climate change and benefits of climate change mitigation, they both had the same proposed solution to the identified problem-government action on climate change mitigation (i.e., gas tax, regulation of carbon emissions, investment in alternative energy, etc.). Including two different pro-climate mitigation framing videos in the stimulus conditions was meant to increase the generalizability of the experiment, as any observed effects from the stimulus are not necessarily due to any one message frame.

A third video was created that emphasized the negative economic costs and impact of proposed government regulations or expenditures on alternative energy and argued against any government action on climate change mitigation (Nisbet, 2009). Each of these interpretative packages was designed to manipulate what considerations were most applicable when considering what the government should do about the problem of climate change.

The videos did not identify any specific sponsor or source so as not to provide any cues that may bias audience information processing. In the noncompetitive and competitive conditions respondents were asked to watch either one or two videos "about global warming and what the government should or should not do about it," again with no specific source or sponsor mentioned in any of the conditions. Finally, the same voice narrator was used in all three videos to further reduce the likelihood of 
any variances in perceived message source. Interested readers can access the stimulus videos on the file sharing service, YouTube. ${ }^{1}$

\section{Research design}

We investigated the hypotheses with a two-wave survey experiment that utilized a nationally representative population sample, administered by the survey firm Knowledge Networks (KN) on behalf of the authors through their internet panel. Their voluntary survey panel was created by $\mathrm{KN}$ through a combination of random digit-dialing (RDD) and address-based sample procedures (ABS) with all individuals who become part of their internet panel being provided with computer hardware or Internet access as needed (more information can be found at http://www.knowledgenetworks.com).

Wave one of the experiment administered a pretest questionnaire assessing baseline attitudes and knowledge about global warming and climate change mitigation policies to a random sample of online panelists. Approximately 4 weeks later, participants from wave 1 were contacted and randomly assigned to one of two stimulus conditions (noncompetitive message environment, competitive message environment), or a control condition. In the noncompetitive message condition, participants viewed a 45-second video promoting government climate change policies, framed either in terms of "environmental disaster" or "national security," followed by a posttest questionnaire evaluating attitude change about climate mitigation. In the competitive message condition, participants viewed one or the other of the pro-climate mitigation videos, but they also viewed a second video arguing against government action on climate mitigation framed in terms of "economic disaster," again followed by a posttest questionnaire. In addition, the order of video presentation within the competitive condition was randomized for participants. In the control condition, participants did not watch any video and simply completed a questionnaire.

Overall, the research design maximized the balance between internal and external validity by randomly assigning adult participants to message conditions, simulating noncompetitive or competitive message environments about climate change, and exposing participants to realistic strategic messages commonly employed by many policy actors. Our randomized control-group pretest-posttest design with a multipleweek interval between pretest and posttest provided the optimal means for assessing the influence of the stimuli on attitude change while controlling for pre-existing attitudes and avoiding any sensitizing or priming effects of the pretest that might bias the results. In total, 594 participants completed both waves of the experiment while those participants who (a) only completed the first wave of the experiment, (b) reported an inability to properly view or hear the videos, (c) failed to play the videos on their computers as tracked by Knowledge Networks, or (d) incorrectly answered a survey question about the topic of the video being excluded from the analysis.

\section{Measured variables}

Several control variables were included in the analyses to ensure any observed differences between treatment groups were not due to significant differences in 
group characteristics or traits including measures of sociodemographics, political ideology, factual knowledge about climate change, and belief in human induced climate change. ${ }^{2}$

In terms of focal variables, open-/closed-mindedness was measured in the study by utilizing three measures from the closed-mindedness component of Kruglanski's (2004) need for closure scale. Participants were asked on the first wave of the study whether they agreed on a 4-point scale with three statements and their answers combined into one index, with open-mindedness coded high $(M=8.5, S D=1.3$, $\alpha=.60){ }^{3}$ In addition, we coded with dichotomous variables whether participants were in the competitive $(35 \%)$ or the noncompetitive $(36 \%)$ message conditions. An indicator of whether the pro-climate mitigation message was framed in terms of the environment or national security was also included in the analysis, with the environment coded high (35\%).

As part of the study design, in both waves of the experiment we asked participants on 7-point Likert scales how costly or how beneficial (each as separate questions) they believed government efforts would be in addressing the problem of climate change (ranging from not costly/not beneficial at all to extremely costly/beneficial). For both waves of the study we created a single measure of perceived cost-benefit calculus by subtracting the perceived cost of government climate change mitigation efforts from the perceived benefits for a score that ranged from -6 to 6 that scored perceived benefits high (wave $1, M=-1.06, S D=2.79$; wave $2, M=-1.37, S D=2.6$ ).

The dependent variable in the analysis was participant attitudes about government policies on climate change mitigation. Participants were asked whether they supported or opposed (on 7-point Likert scales) eight different policy options promoting climate change mitigation and their responses combined into one additive index, with support for government policies promoting climate change mitigation coded high. ${ }^{4}$ The questions were asked on the first wave of the survey $(M=32.4, S D=10.5$, $\alpha=.85)$ and then again on the second wave of the survey $(M=33.2, S D=10.7$, $\alpha=.88$ ) after message exposure.

\section{Results}

\section{Manipulation check}

In order to assess whether the framing manipulations successfully influenced the applicability of the considerations audiences employ to form an opinion about climate change mitigation, a manipulation check was conducted. Participants were asked to rank order five sets of considerations about government policy on climate change both in the pretest and posttest. ${ }^{5}$ Analysis of the results demonstrated that controlling for sociodemographics and wave one responses, participants in the noncompetitive national security condition ranked national security considerations more applicable, $t(562)=3.408, p \leq .01$, than the control condition. However, applicability of national security was not significantly different from the control condition in the competitive condition. Likewise, participants in the noncompetitive 
environmental disaster condition believed environmental considerations were significantly more applicable compared to the control condition, $t(562)=2.340$, $p \leq .05$, but did not differ significantly from control in the competitive environmental disaster condition. Furthermore, we examined whether the applicability of economic cost of climate change mitigation considerations significantly differed across the conditions, $t(562)=0.082, p=$ n.s., and they did not. This pattern of results is consistent with Chong and Druckman's (2007b) findings regarding the influence of noncompetitive vs. competitive frame exposure on applicability.

We also attempted to evaluate the "strength" of the competing frames by asking respondents how "credible" they found the videos they viewed, each on a 5-point Likert scale. A paired-samples T-test determined the difference between mean ratings of credibility for the environmental disaster frame $(M=3.0, S D=1.3)$ and the economic costs frame $(M=2.9, S D=1.2)$ was not significant, $t(80)=0.766, p=$ n.s. Neither was the difference, $t(75)=1.168, p=$ n.s., between the mean credibility rating of the national security frame $(M=2.8, S D=1.1)$ and the economic costs frame $(M=2.7, S D=1.0)$. These results reassure us that subjects in the competitive frame condition perceived the message frames as having relative equal credibility, as an indicator of "strength," and thus any observed differences between the conditions were not based on either the pro- or anti-climate change mitigation frames being viewed as fundamentally more "credible" than the other.

\section{Analyses}

In all our analyses, OLS regression was employed to test our hypotheses and research question. We employed OLS regression in order to avoid the increased risk of type I and type II errors that can occur when continuous independent variables are converted into categorical variables for use in analysis of variance (ANOVA) tests (see Hayes, 2005, pp. 473-479 for discussion). First, it was tested whether support for climate mitigation differed as a result of viewing a strategic framing message alone or in competition with another message. Individual's support for climate mitigation - the dependent variable - was measured at two time points and therefore, models predicted individual's support for climate mitigation at the second time point, controlling for the individual's opinion at the first time point (see Cohen et al., 2003). Results thus demonstrate whether there is evidence that the framing messages were associated with attitude change between the pretest and posttest.

In this first OLS regression model, results showed that there were no differences between those who viewed a pro-climate change mitigation change video and those who did not view any video, regardless of whether the announcement was shown alone (the noncompetitive framing condition, $b=-.108$, $p=$ n.s., see Table 1, Model 1) or in conjunction with an anti-climate change mitigation policy message frame (the competitive framing condition, $b=.362, p=$ n.s.), disconfirming H1. Apart from an individual's prior level of support for climate mitigation policy, political ideology and whether an individual believed in human induced climate change were 
Table 1 Results of Models Predicting a Change in Support for Climate Change Mitigation Policy

\begin{tabular}{lcc}
\hline & Model 1 & Model 2 \\
\hline Intercept & $10.307^{* *}$ & $12.546^{* * *}$ \\
Education & -.148 & -.151 \\
Age & .012 & .013 \\
Female & -.295 & -.238 \\
Income & .052 & .051 \\
White & -.013 & -.155 \\
Political ideology & $-.721^{* * *}$ & $-.643^{* *}$ \\
Knowledge about climate change & -.238 & -.280 \\
Belief in human induced climate change & $1.264^{*}$ & $1.296^{*}$ \\
Open-mindedness (mean-centered) & .197 & -.317 \\
Theme & .734 & .737 \\
Wave 1 support for climate policy & $.811^{* * *}$ & $.816^{* * *}$ \\
Competitive & .362 & .364 \\
Noncompetitive & -.036 \\
Competitive $^{*}$ open-mindedness & -.108 & $1.136^{*}$ \\
Noncompetitive $^{*}$ open-mindedness & - & .358 \\
$R^{2}$ (wave 2 support for climate mitigation) & - & .781 \\
\hline
\end{tabular}

Note: All entries are unstandardized regression coefficients $(b)$.

${ }^{a}$ Control condition is the reference category.

${ }^{*} p<.05 .{ }^{* *} p<.01 .{ }^{* * *} p<.001$.

the only significant factors predicting an individual's support for climate mitigation policy; unsurprisingly, individuals who believed in human-induced climate change $(b=1.264, p \leq .05)$ and who were more politically liberal $(b=1.264, p \leq .001)$ were more supportive of climate change mitigation policy.

We also examined whether there was any evidence supporting our second hypothesis (H2), that the effect of viewing a message differs according to the open/closed-mindedness of an individual. Our second OLS regression model shows that the effect of viewing a message frame promoting government action on climate change, when it was in competition with an anti-climate change mitigation message, depended upon the open-/closed-mindedness of an individual, $b=1.136, p \leq .05$, see Table 1, Model 2, and Figure 1. There was no evidence that the effect of viewing a climate change PSA by itself - the noncompetition condition-depended on open/closed-mindedness, $b=.358, p=$ n.s. Among individuals who were relatively more open-minded (individuals at one standard deviation above the mean for open/closed-mindedness), viewing a climate change mitigation video in competition with an anti-climate change video resulted in more support for climate change mitigation policy than those in the control condition, $b=2.032, p \leq .05$. There was no difference between those in the control condition and those in the competitive condition among people at the mean level of open-/closed-mindedness or among 


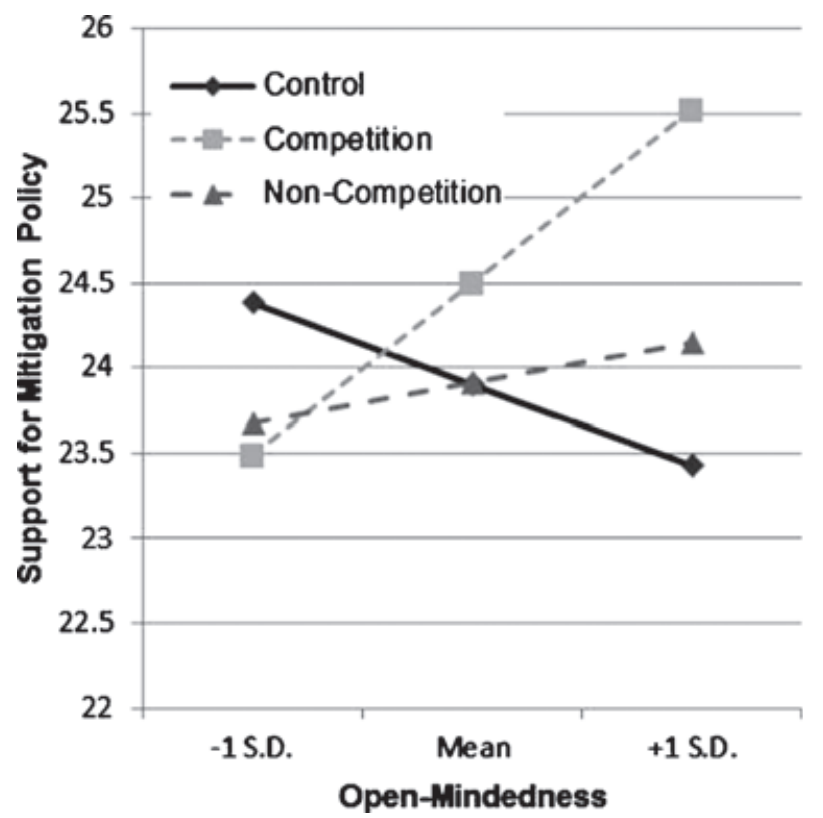

Figure 1 Effect of open-mindedness across framing conditions. Note: Support for climate mitigation policy scale ranged from 8 to 32 .

those who were relatively closed-minded. In sum, these results show that viewing a pro-mitigation video paired with an anti-mitigation video can shift opinions to be more supportive of climate change policy among those who are open-minded, supporting $\mathrm{H} 2$, but no evidence of significant attitude change among either open- or closed-minded participants in the noncompetitive condition, disconfirming $\mathrm{H} 1$.

Finally, in order to evaluate our third and fourth hypotheses about the relationship between open-/closed-mindedness, perceived costs/benefits, and attitude change we evaluated whether an individual's assessment of the costs verses the benefits of government climate change mitigation policy was a mediating variable between message exposure and climate change attitudes. In other words, did competitive message exposure lead to a change in an individual's cost-benefit calculus about government action on climate change, which in turn led to a change in attitude about government climate change mitigation policy? In addition, we assessed whether the perceived cost-benefit calculus was a moderated-mediator of the relationship between competitive message exposure and attitude change by evaluating the influence of message exposure on an individual's cost-benefit calculus varied by their degree of open-/closed-mindedness. In order to test these relationships we employed the MODMED SPSS macro as described in Preacher, Rucker, and Hayes (2007).

Results of the analysis demonstrate that the pro-climate change mitigation message effect on attitude change in the competitive environment is at least partially carried through individual's assessment of the cost-benefit calculus (supporting H3), but 
Table 2 Results of Moderated Mediation Models Predicting Change in Climate Change Mitigation Policy Support

\begin{tabular}{|c|c|c|c|}
\hline & \multicolumn{3}{|c|}{ Mediator } \\
\hline & $\mathrm{C} / \mathrm{B}$ calculus & Costs & Benefits \\
\hline \multicolumn{4}{|l|}{ Equation predicting mediator (Wave 2) } \\
\hline Intercept & $-1.573^{*}$ & $3.536^{* *}$ & $1.660^{* * *}$ \\
\hline Education & -.050 & .015 & -.042 \\
\hline Age & -.002 & .005 & .002 \\
\hline Female & -.168 & .053 & -.118 \\
\hline Income & .000 & -.006 & -.008 \\
\hline White & -.162 & .092 & -.090 \\
\hline Political ideology & $-.241^{* * *}$ & $.124^{* *}$ & $-.130^{* *}$ \\
\hline Knowledge about climate change & .014 & .040 & .037 \\
\hline Belief in human induced climate change & .034 & .059 & .134 \\
\hline Open-mindedness (mean centered) & -.106 & .002 & -.115 \\
\hline Theme & -.181 & .030 & -.164 \\
\hline Wave 1 support for climate change mitigation policy & $.082^{* * *}$ & $-.024^{* * *}$ & $.067^{* * *}$ \\
\hline Wave 1 mediator & $.377^{* * *}$ & $.286^{* * *}$ & $.330^{* * *}$ \\
\hline Competitive $^{\mathrm{b}}$ & -.1014 & .086 & .013 \\
\hline Noncompetitive $\mathrm{b}^{\mathrm{b}}$ & -.070 & .205 & .154 \\
\hline Competitive $^{*}$ open-mindedness & $.352^{*}$ & -.088 & $.283^{* *}$ \\
\hline Noncompetitive open-mindedness & .131 & .020 & .167 \\
\hline \multicolumn{4}{|c|}{ Equation predicting support for climate change mitigation policy (Wave 2) } \\
\hline Intercept & $11.531^{* * *}$ & $11.552^{* * *}$ & $6.705^{* * *}$ \\
\hline Education & -.078 & -.144 & -.074 \\
\hline Age & .022 & .016 & .018 \\
\hline Female & -.130 & -.229 & -.134 \\
\hline Income & .065 & .052 & .080 \\
\hline White & .020 & -.127 & -.036 \\
\hline Political ideology & $-.404^{*}$ & $-.587^{* *}$ & $-.462^{*}$ \\
\hline Knowledge about climate change & -.252 & -.253 & $-.327^{\mathrm{a}}$ \\
\hline Belief in human induced climate change & $1.051^{\mathrm{a}}$ & $1.284^{*}$ & .718 \\
\hline Open-mindedness (mean centered) & -.266 & -.336 & -.226 \\
\hline Theme & $.955^{\mathrm{a}}$ & .757 & $1.039^{*}$ \\
\hline Wave 1 mediator & -.061 & -.037 & -.036 \\
\hline Wave 2 mediator & $.816^{* * *}$ & $-.316^{\mathrm{a}}$ & $1.363^{* * *}$ \\
\hline Wave 1 support for climate change mitigation policy & $.714^{* * *}$ & $.806^{* * *}$ & $.680^{* * *}$ \\
\hline Competitive $^{\mathrm{b}}$ & .376 & .373 & .290 \\
\hline Noncompetitive $^{\mathrm{b}}$ & -.044 & .006 & -.307 \\
\hline Competitive ${ }^{*}$ open-mindedness & $.881^{\mathrm{a}}$ & $1.136^{*}$ & $.828^{\mathrm{a}}$ \\
\hline Noncompetitive $^{*}$ open-mindedness & .265 & .400 & .134 \\
\hline
\end{tabular}

All entries are unstandardized regression coefficients $(b)$. ${ }^{\mathrm{a}} p<.10$; ${ }^{\mathrm{b}}$ Control condition is the reference category.

${ }^{*} p<.05 .{ }^{* *} p<.01 .{ }^{* *} p<.001$. 
that the exact nature of how viewing a message frame in a competitive environment influences support for policy through perception of the cost-benefit calculus is dependent upon that individual's level of open-/closed-mindedness (see Table 2), in answer to H4. For those individuals low in open-mindedness (see Table 3), viewing a pro-climate change mitigation message in competition with an anti-climate change mitigation message resulted in a decreased cost-benefit calculus, which then led to a decline in support for government climate change mitigation policy. For individuals between one-and-a-half standard deviations below the mean of open-mindedness and two standard deviations above the mean of open-mindedness, viewing a proclimate change mitigation video in competition had no effect on attitudes (either directly or indirectly through perception of the cost-benefit calculus). At high levels of open-mindedness (two standard deviations above the mean), there was evidence that viewing the message frame in competition resulted in a more favorable cost-benefit calculus, leading to more support for climate change mitigation policy (see Table 3).

To probe this finding more deeply, we next conducted separate analyses replacing the cost-benefit calculus with costs and benefits as the mediator, respectively. These analyses allow us to see whether viewing a video in competition moves the costs, the benefits, or both simultaneously. Results are presented in Tables 2 and 3. It appears that most of the effect observed in the cost-benefits calculus model is attributable to movement in perceived benefits, rather than in perceived costs. The indirect effect of viewing a message in competition was never significant through perceived costs, but the pattern of indirect effects through perceived benefits mirrored (even magnified) the effect through the calculus. These data reveal that viewing a message in competition decreased the perceived benefits among those who were

Table 3 Indirect Effect of Viewing a PSA in Competition (in Comparison to the Control Condition) on Change in Climate Change Mitigation Policy Support Through Mediators, at Various Levels of Open-Mindedness

\begin{tabular}{lccc}
\hline & \multicolumn{3}{c}{ Mediator } \\
\cline { 2 - 4 } Value of open-mindedness & Cost-benefit calculus & Costs & Benefits \\
\hline Scale minimum $(x=3)$ & $-1.664^{*}$ & -.180 & $-2.105^{*}$ \\
3 SD below the mean $(x=4.610)$ & $-1.201^{*}$ & -.135 & $-1.484^{*}$ \\
2 SD below the mean $(x=5.907)$ & $-.829^{*}$ & -.099 & $-.984^{*}$ \\
1 SD below the mean $(x=7.204)$ & $-.439^{\mathrm{a}}$ & -.061 & $-.460^{\mathrm{a}}$ \\
Mean $(x=8.5017)$ & -.078 & -.023 & .022 \\
1 SD above the mean $(x=9.799)$ & .281 & .008 & $.505^{\mathrm{a}}$ \\
2 SD above the mean $(x=11.096)$ & $.664^{\mathrm{a}}$ & .045 & $1.019^{*}$ \\
Scale maximum $(x=12)$ & $.923^{\mathrm{a}}$ & .070 & $1.367^{*}$ \\
\hline
\end{tabular}

${ }^{\mathrm{a}} p<.10$.

${ }^{*} p<.05 .{ }^{* *} p<.01 .{ }^{* * *} p<.001$. 
less open-minded, resulting in less support for climate change mitigation policy; on the flip side, among those who were relatedly more open-minded, viewing a video in competition increased the perceived benefits, resulting in an increase in support for climate change mitigation policy in comparison to those who saw no video.

\section{Discussion}

\section{Theoretical contributions}

Scholarship on framing effects on attitude change in recent years has proceeded along two tracks (a) focusing on identifying individual differences that may moderate the effects of frame exposure and (b) examining framing effects within competitive and noncompetitive information environments. This study uniquely combines these two areas of scholarship by simulating the competitive framing contest about climate change mitigation at the macro level of analysis and then evaluating the effects of frame exposure at the micro, or individual, level of analysis, while simultaneously taking into account individual differences amongst the audience. Our findings demonstrate that research asserting that framing effects on attitudes are negated when individuals are exposed to equally strong competing message frames has an important boundary condition as framing effects may be contingent upon individual differences - in this case the relative degree of open-/closed-mindedness of the audience.

Why was our first hypothesis, that attitude change was more likely in the noncompetitive condition than the competitive condition, rejected? The reason may be that the longstanding, intense frame competition about climate change has created such a high degree of opinion polarization and reliance on prior opinions that a single exposure to commonly employed message frames is generally ineffective at inducing attitude change about climate change mitigation, even among open-minded individuals. We suggest that attitude change in the competitive message conditions appears to result from the interaction of two key factors: (a) the stimulus to process a wider range of considerations in a deliberative, systematic manner due to the presentation of two equally strong competing message frames and (b) greater openmindedness which lends itself to the processing of larger amounts of information in a systematic manner, less preference for the status-quo, less risk aversions, and greater attentiveness to perceived benefits.

In other words, the findings of our study are consistent with the idea that the competitive framing condition motivates open-minded participants to weigh the overall benefits of climate change mitigation to a much greater degree than closed-minded participants, which influenced their overall cost-benefit calculation regarding climate change policies, and consequently increased their support for government action on climate change mitigation. In contrast, closed-minded individuals prefer the status-quo, are less open to change, and are more likely to "seize" on initial opinions in order to avoid systematic deliberation of alternatives, Thus, in our study examining a highly salient and polarized issue such as climate change, in retrospect it 
is less surprising that closed-minded individuals demonstrate no significant change in opinion compared to the control group in either set of message conditions.

There are several areas that future research may build on from this study. For example, as we mentioned climate change mitigation is a highly polarized political issue with audiences engaging in a high degree of motivated reasoning when processing information about the topic (Hart \& Nisbet, 2012). Future research may examine how competitive/noncompetitive framing may interact with open-/closedmindedness to influence attitude change either (a) when "strong" versus "weak" frames are paired in a competitive message environment rather than "strong" versus "strong" as in this study or (b) around a less ideologically polarizing or salient topic than climate change.

Second, our study reinforces the need for additional communication research on the role that open-/closed-mindedness, and other closely related constructs, may play in opinion formation. For example, greater closed-mindedness has been found to be positively correlated with such orientations as conservatism, authoritarianism, intolerance of ambiguity, and dogmatism (e.g., Jost, Glaser, Kruglanski, \& Sulloway, 2003; Kruglanski, 2004; Webster \& Kruglanski, 1994). Though some scholars dispute the positive correlation between closed-mindedness and conservative ideology (i.e., Greenberg \& Jonas, 2003) by arguing that liberal individuals may equally be closedminded, Kruglanski (2004) asserts that individuals with a high need for closure are attracted specifically to belief systems "promising stability and inequality" more so than others (p. 148).

In our view the findings of this study and the scholarship on need for closure, and other similar orientations (i.e., dogmatism, authoritarianism, system justification theory, etc.), raise two overlapping pathways for future communication research. First, our study controlled for political ideology and in a post hoc test found no interactions between ideology and message conditions. This suggests to us that framing scholars that often focus on values and belief systems as individual differences that moderate framing/message effects may want to turn their focus to consider a wider range of more fundamental individual differences such as need for closure, dogmatism, system justification, etc. This broader focus is especially relevant when considering frames or issues that focus on questions of stability vs. change, inequality vs. equality, and risks vs. benefits that are inherent to many critical, environmental, health, economic, and social issues. In other words, in some cases the moderating influence of ideology or values on framing and/or message effects may be spurious and instead be driven by more fundamental orientations like need for closure that influence individuals to self-select into specific types of belief or value systems that venerate the status quo or inequality.

A second pathway for communication research is how need for closure is associated with factual misperceptions or false beliefs. Our increasingly politically polarized media environment and audience segmentation has led communication scholars to recently debate the nature of selective attention/exposure and media effects (e.g., Bennett \& Iyengar, 2008). Many pundits and policy-makers have lamented 
the growth of "epistemic closure" in policy debates (e.g., Cohen, 2010) whereas audiences heavily rely on ideologically congruent, homogenous information sources to the exclusion of all others, resulting in large ideologically driven perception gaps. Scholarship across several disciplines has increasingly found the venerable maxim that "everyone is entitled to their own opinion, but not their own facts" holds less sway across large segments of the public with false beliefs difficult to correct (e.g., Berinsky, 2012; Garrett, Nisbet, \& Lynch, 2011; Nyhan \& Reifler, 2010; Schwarz, Sanna, Skurnik, \& Yoon, 2007; World Public Opinion, 2006). The role of need for closure in motivating selective exposure and attention to ideologically or value congruent information and/or resisting corrective messages intended to update false beliefs or misperceptions is a research area that deserves more explication.

\section{Limitations}

In light of our theoretical contributions of our findings, some key limitations of our study should be noted. The strength of our study is that it was a multiwave online experiment with a nationally representative adult sample that maximized our external validity and provided conservative estimates of attitude change. However, this strong external validity was paired with some loss in internal control as the experiment was conducted outside the lab and employed videos rather than relying on simple textual stimuli. Furthermore, though our results are consistent with the cognitive processes that we have outlined, we are unable to assess key cognitive processes such as selective attention, motivation, need for cognition, or depth of processing within the context of our research design. Thus, our study leaves some important questions on the exact nature of the cognitive processes at work unanswered, but in turn provides fodder for future research. Overall we believe that many of these deficits were compensated for by the increased external validity of testing naturalistic stimulus materials representing common competing message frames about climate change that audiences are typically exposed to in public discourse.

Another question that remains is whether our findings are generalizable to framing effects on topics other than climate change. Our design was limited by not including stimulus sampling across different policy contexts. Moving forward, replicating this study simultaneously across several policy contexts would provide further evidence on how need for closure may or may not influence framing effects in competitive message environments. In addition, manipulating frames to explicitly focus on stability versus change, or inequality versus equality, may further elucidate how need for closure moderates message effects when considering these competing policy tradeoffs.

\section{Implications}

What lessons do our findings have for strategic communication about policy issues? Our study was not an attempt to simulate exposure to political advertising specifically, either in terms of single-sided or two-sided messages. Rather, our study attempts to experimentally simulate how exposure to competing frames in mass communication, 
broadly defined (e.g., news media, political discourse, etc. — see Chong and Druckman, 2007a), influences opinion formation about public policy. Our results suggest framing effects on such a highly ideologically polarized, salient issue as climate change are extremely difficult to induce, even when exposing audiences to frames in a noncompetitive environment. However, our findings also imply that simultaneous exposure to competing frames increases audience motivations to weigh a larger set of applicable considerations when making policy judgments, especially when communicating policy trade-offs or costs and/or benefits. In turn, this competitive communication may lead to attitude change among some audience segments that are more open-minded.

Three implications specific to strategic communication about climate change also emerge. First, several scholars and practitioners have focused on segmenting the public in terms of climate change communication across a range of dimensions (e.g., Maibach, Roser-Renouf, \& Leiserowitz, 2008). In this context, climate change communicators may wish to focus on identifying which audience segments are more likely to be "open-minded" than others and prioritize those segments for targeted communications that stimulate greater consideration of the costs and benefits of climate change mitigation. This strategy may be an effective means of inducing attitude change that bridges some of the polarized ideological divide around the issue.

A second implication is the need for more work on developing communication strategies that may appeal to population segments with a greater need for closure. For instance, just as open-minded individuals may be more responsive to pro-climate mitigation frames that highlight benefits of changing the status quo, a question that remains unanswered is whether closed-minded individuals would be more responsive to pro-climate mitigation messages that frame the issue in terms of maintaining the status quo (e.g., in terms of economic status, social hierarchy, political power, lifestyle, etc.). The work of Feygina, Jost, and Goldsmith (2010) on the influence of system-justification orientations, a closely related construct to need for closure, provides some empirical basis for this approach. Within their study the framing of pro-environmental efforts as maintaining the status quo was an effective means to increase support for signing a proenvironmental petition among individuals with high system-justification tendencies. A similar approach may work among those with a high need for closure.

Lastly, in recent years scientists and environmental advocates have been concerned that the so-called "climate denialist movement," paired with negative media coverage about climate science such as "Climategate," have been negative influences on public opinion toward climate mitigation (see Dunlap \& McCright, 2011, for example). This study indicates that such concern may be somewhat overstated. In fact, the presence of competitive frames in public discourse may stimulate some segments of the public to more carefully deliberate about the tradeoffs of climate change policies, and consequently increase their support for climate mitigation rather than diminish it. 


\section{Acknowledgments}

This research was supported by the Ohio State University School of Communication Miller Research Award, a National Science Foundation Grant (SES-0752876), and the Cornell University Agricultural Experiment Station federal formula funds, Project No. NYC-131405, received from Cooperative State Research, Education, and Extension Service, U.S. Department of Agriculture. Although this research was supported by these organizations, any opinions, findings, conclusions, or recommendations expressed in this publication are those of the authors and do not necessarily reflect the views of these organizations.

\section{Notes}

1 The web addresses for the stimuli are (a) environmental disaster frame-http://youtu.be/IVNRA-UIytc, (b) national security frame-http://youtu.be/PmODFzbV0kQ, (c) economic costs frame-http://youtu.be/fvo7CVVBAHE.

2 Controls include age $(M=49.9, S D=15.2)$, gender ( $50 \%$ women), and race ( $77 \%$ white). Household income was measured on a 19-point scale with the median household income $\$ 40,000-\$ 49,999(M=10.3, S D=2.0)$. Educational attainment was measured on a 14-point scale with the median attainment a high school diploma $(M=12.0, S D=3.9)$. Ideology was measured on a 7-point scale from very liberal to very conservative $(M=4.3$, $S D=1.5)$. Knowledge about climate change was gauged by five true/false questions combined into an index ranging from zero to five $(M=2.0, S D=1.24)$. Participants were asked (a) "the hole in the ozone layer is the primary cause of global warming" (false), (b) "the average temperature of the earth has increased significantly in the last 100 years" (true), (c) "China is the largest emitter of carbon dioxide (the greenhouse gas that has been linked to global warming) in the world" (true), (d) "greater output from the Sun contributes to global warming more so than greenhouse gases produced by people" (false), (e) "reducing human emissions of greenhouse gases will have an immediate effect on global warming with average global temperatures dropping in just a few years" (false). Agreement with "Global warming is happening, and is mostly caused by human activities" (49.5\%) was included as a dichotomous variable.

3 Participants were asked whether they agree or disagree (a) "Even after I have made up my mind about something, I am always eager to consider a different opinion," (b) "When thinking about a problem, I consider as many different opinions on the issue as possible," (c) "I usually do not consult many different opinions before forming my own view" (reverse coded).

4 Participants were asked about support for eight policies: (a) "Create a 'Cap and Trade' policy that limits greenhouse gases said to cause global warming," (b) "Do nothing to directly address global warming but rather limit government regulation, spending, and taxation in order to encourage economic growth" (reverse-coded), (c) "increase the federal tax on gasoline by $\$ .10$ per gallon as a means to reduce oil dependence and carbon emissions," (d) "Increase mandatory government mileage standards for cars and trucks to increase fuel efficiency," (e) "develop a new international treaty on global climate change that would replace the 1997 Kyoto Treaty and require the United States to cut its emissions of carbon dioxide $80 \%$ by the year 2050," (f) "increase government spending toward 
developing alternative energy and creating new 'green' jobs," (g) "let the free market, economic competition, and technology attempt to address global warming without government action" (reverse coded), (h) "Create a 'carbon tax' that directly taxes companies that emit greenhouse gases said to cause global warming with a fixed fee per ton of pollutants released into the atmosphere."

5 Participants ranked the applicability of five considerations about government action on climate change: (a) "Reducing U.S. reliance on foreign oil and support for foreign terrorism," (b) "Creating high-paying 'green' jobs and a new 'green' economy based on alternative energy," (c) "Preventing environmental disasters and saving endangered plants and animals," (d) "The economic costs of reducing carbon emissions and more government regulations or taxes," (e) "Whether global warming is primarily caused by humans or by natural causes."

\section{References}

Benford, R., \& Snow, D. (2000). Framing processes and social movements: An overview and assessment. Annual Review of Sociology, 26, 611-639. doi: 10.1146/annurev.soc.26.1.611

Bennett, W. L., \& Iyengar, S. (2008). A new era of minimal effects? The changing foundations of political communication. Journal of Communication, 58(4), 707-731. doi: 10.1111/j.1460- 2466.2008.00410.x

Berinsky, A. J. (2012). The birthers are back. From http://today.yougov.com/news/2012/02/03/birthers-are-back/.

Borah, P. (2011a). Conceptual issues in framing: A systematic examination of a decade's literature. Journal of Communication, 61(2), 246-263. doi: 10.1111/j.14602466.2011.01539.x

Borah, P. (2011b). Seeking more information and conversations: Influence of competitive frames and motivated processing. Communication Research, 38(3), 303-325. doi: $10.1177 / 0093650210376190$

Choi, J. A., Koo, M., Choi, I., \& Auh, S. (2008). Need for cognitive closure and information search strategy. Psychology and Marketing, 25(11), 1027-1042. doi: 10.1002/mar.20253

Chong, D., \& Druckman, J. N. (2007a). Framing theory. Annual Review of Political Science, 10, 103-126. doi: 10.1146/annurev.polisci.10.072805.103054

Chong, D., \& Druckman, J. N. (2007b). A theory of framing and opinion formation in competitive elite environments. Journal of Communication, 57, 99-118. doi: 10.1111/j.1460- 2466.2006.00331.x

Chong, D., \& Druckman, J. N. (2007c). Framing public opinion in competitive democracies. American Political Science Review, 101(4), 637-655. doi: 10.1017/S0003055407070554

Cohen, P. (2010, April 27). 'Epistemic closure'? Those are fighting words. New York Times, p. C1.

Dijksterhuis, A., van Knippenberg, A., Kruglanski, A. W., \& Schaper, C. (1996). Motivated social cognition: Need for closure effects on memory and judgment. Journal of Experimental Social Psychology, 32, 254-270. doi: 10.1006/jesp.1996.0012

Dunlap, R. E., \& McCright, A. (2011). Organized climate change denial. In J. Dryzek, R. Norgaard, \& D. Schlosberg (Eds.), Oxford handbook of climate change and society (pp. 144-160). Cambridge, England: Oxford University Press.

Entman, R. M. (2004). Projections of power: Framing news, public opinion, and US foreign policy. Chicago, IL: University of Chicago Press. 
Feygina, I., Jost, J. T., \& Goldsmith, R. E. (2010). System justification, the denial of global warming, and the possibility of "system sanctioned change." Personality and Social Psychology Bulletin, 36(3), 326-338. doi: 10.1177/0146167209351435

Gamson, W., \& Modogliani, A. (1989). Media discourse and public opinion on nuclear power: A constructionist approach. The American Journal of Sociology, 95, 1-37. doi: $10.1177 / 1940161211425410$

Garrett, R. K., Nisbet, E. C., \& Lynch, E. (2011, November). Undermining the corrective effects of media-based political fact checking. Paper presented at the Annual Conference of the National Communication Association, New Orleans, LA.

Greenberg, J., \& Jonas, E. (2003). Political motives and political orientation — the left, the right, and the rigid: Comment on Jost et al. (2003). Psychological Bulletin, 129, 3376-3382. doi: 10.1037/0033-2909.129.3.376

Hart, P. S., \& Nisbet, E. C. (2012). Boomerang effects in science communication: How motivated reasoning and identity cues amplify opinion polarization about climate mitigation policies. Communication Research, 39, 701-723. doi: $10.1177 / 0093650211416646$

Holbert, R. L., \& Hansen, G. J. (2006). Fahrenheit 9-11, need for closure, and the priming of affective ambivalence: An assessment of intra-affective structures by party identification. Human Communication Research, 32, 109-129. doi: 10.1111/j.1468-2958.2006.00005.x

Jost, J. T., Glaser, J., Kruglanski, A. W., \& Sulloway, F. J. (2003). Political social conservatism as motivated social cognition. Psychological Bulletin, 129, 339-375. doi: 10.1037/ 0033-2909.129.3.339

Jost, J. T., \& Hunyady, O. (2005). Antecedents and consequences of system-justifying ideologies. Current Directions in Psychological Science, 14, 260-265. doi: 10.1111/ j.0963-7214.2005.00377.x

Kahn, M.E. \& Kotchen, M.J. (2010). Environmental concern and the business cycle: The chilling effect of recession. NBER Working Paper 16241. Retrieved May 30, 2012, from http://www.nber.org/papers/w16241.

Kahneman, D., \& Tversky, A. (1984). Choices, values, and frames. American Psychologist, 39(4), 341-350. doi: 10.1037/0003-066X.39.4.341

Kruglanski, A. W. (2004). The psychology of closed-mindedness. New York: Psychology Press.

Kruglanski, A. W., Webster, D. M., \& Klem, A. (1993). Motivated resistance and openness to persuasion in the presence or absence of prior information. Journal of Personality and Social Psychology, 65(5), 861-876. doi: 10.1037/0022-3514.65.5.861

Maibach, E. W., Roser-Renouf, C., \& Leiserowitz, A. (2008). Communication and marketing as climate-change intervention assets. American Journal of Preventive Medicine, 35(5), 488-500. doi: 10.1016/j.amepre.2008.08.016

Moser, C. (2010). Communicating climate change: History, challenges, process and future directions. Wiley Interdisciplinary Reviews: Climate Change, 1(1), 31-53. doi: $10.1002 /$ wcc. 11

Nisbet, M. C. (2009). Communicating climate change: Why frames matter for public engagement. Environment, 51(2), 12-23. doi: 10.3200/ENVT.51.2.12-23

Nyhan, B., \& Reifler, J. (2010). When corrections fail: The persistence of political misperceptions. Political Behavior, 32(2), 303-330. doi: 10.1007/s11109-010-9112-2

Richter, L., \& Kruglanski, A. W. (2004). Motivated closed mindedness and the emergence of culture. In M. Schaller \& C. S. Crandall (Eds.), The psychological foundations of culture (pp. 101-121). Mahwah, NJ: Lawrence Erlbaum Associates. 
Scheufele, D., \& Tewksbury, D. (2007). Framing, agenda setting, and priming: The evolution of three media effects models. Journal of Communication, 57, 9-20. doi: 10.1111/j.00219916.2007.00326.x

Schwarz, N., Sanna, L. J., Skurnik, I., \& Yoon, C. (2007). Metacognitive experiences and the intricacies of setting people straight: Implications for debiasing and public information campaigns. In M. P. Zanna (Ed.), Advances in experimental social psychology (Vol. 39, pp. 127-161). New York, NY: Academic Press.

Sinatra, G., Kardash, C., Taasoobshirazi, G., \& Lombardi, D. (2011). Promoting attitude change and expressed willingness to take action toward climate change in college students. Instructional Science, 40, 1-17. doi: 10.1007/s11251-011-9166-5

Sniderman, P. M., \& Theriault, S. M. (2004). The structure of political argument and the logic of issue framing. In W. E. Saris \& P. M. Sniderman (Eds.), Studies in public opinion (pp. 133-165). Princeton, NJ: Princeton University Press.

Sunstein, C. R. (2006). The availability heuristic, intuitive cost-benefit analysis, and climate change. Climatic Change, 77(1-2), 195-210. doi: 10.1007/s10584-006-9073-y

Weber, E. U. (2010). What shapes perceptions of climate change? Wiley Interdisciplinary Reviews: Climate Change, 1(3), 332-342. doi: 10.1002/wcc.41

Webster, D. M., \& Kruglanski, A. W. (1994). Individual differences in need for cognitive closure. Journal of Personality and Social Psychology, 67(6), 1049-1062. doi: 10.1037/0022-3514.67.6.1049

World Public Opinion (2006). Percentage of Americans believing Iraq had WMD rises. Washington, DC: World Public Opinion: Global Public Opinion on International Affairs.

Zia, A., \& Todd, A. M. (2010). Evaluating the effects of ideology on public understanding of climate science: How to improve communication across ideological divides? Public Understanding of Science, 19(6), 743-761. doi: 10.1177/0963662509357871 